\title{
DESENVOLVIMENTO DO EMPREENDEDORISMO EM MEIO AO COMÉRCIO ELETRÔNICO: UM ESTUDO DE CASO.
}

\author{
Marissa Yanara de Godoy Lima, Josélia Galiciano Pedro, Nilmaer Souza da Silva \\ Universidade do Oeste Paulista - UINOESTE. E-mail: joselia@unoeste.br
}

\section{RESUMO}

Mediante a imposição do fenômeno da globalização e as constantes tentativas de estabilização da economia brasileira, grandes organizações, responsáveis por parte considerável dos empregos não resistiram às dificuldades e tiveram de encerrar suas atividades, dispensando a mão de obra de milhares de trabalhadores. Visto a situação em que encontravam-se, muitos destes trabalhadores, a fim de garantir seu sustento, arriscaram-se e mesmo sem qualquer capacitação ou experiência abriram seu próprio negócio. A partir de 1995, com a popularização da internet tornou-se possível a prática de comércio eletrônico, onde muitos empreendedores, atraídos pelo baixo investimento necessário, lançaram-se neste novo segmento e passaram a ofertar seus produtos e serviços por meio da rede mundial de computadores. Esta pesquisa se justificou por demonstrar de que maneira um empreendedor identifica a oportunidade de ingressar no mundo dos negócios por meio do seu próprio empreendimento, sendo este pertencente ao comércio eletrônico, e por meio de uma empresa de comercialização eletrônica exemplificar de que forma um empreendedor pode usufruir das oportunidades oferecidas pela internet e conquistar o seu espaço perante o concorrido comércio eletrônico. No que se refere às características metodológicas, esta pesquisa foi efetuada de forma exploratória, baseada em uma abordagem qualitativa, utilizando métodos de estudo de caso. Desta forma, os resultados enfatizaram a importância do empreendedorismo em meio ao cenário atual, com ênfase nas práticas de comércio eletrônico bem como as modalidades que este aborda, evidenciando essencialmente os benefícios e as barreiras encontradas pelo empreendedor que opta por este segmento.

Palavras-chave: Empreendedorismo, Comércio Eletrônico, Internet.

\section{DEVELOPMENT OF ENTREPRENEURSHIP IN HALF TO E-COMMERCE: A CASE STUDY.}

\begin{abstract}
By imposing the phenomenon of globalization and the constant attempts to stabilize the Brazilian economy, large organizations, responsible for a considerable proportion of the jobs did not withstand the difficulties and had to close their businesses, eliminating the labor of thousands of workers. Since the situation in which they found themselves, many of these workers in order to ensure their livelihood, and even ventured without any training or experience opened his own business. From 1995, with the popularization of the Internet made possible the practice of ecommerce, where many entrepreneurs, attracted by the low investment required, embarked on this new segment and began to offer its products and services through the worldwide network of computers. This research was justified by showing how an entrepreneur identifies an opportunity to enter the business world through his own business, and this belongs to ecommerce, and through an electronic trading company exemplify how an entrepreneur can take advantage of the opportunities offered by the Internet and conquer your space before the competitive ecommerce. With regard to methodological characteristics, this research was conducted in an exploratory manner, based on a qualitative approach, using case study methods. Thus, the results emphasized
\end{abstract}


the importance of entrepreneurship amid the current scenario, with an emphasis on e-commerce practices and arrangements that this approach essentially highlighting the benefits and barriers faced by the entrepreneur that chooses this segment.

Keywords: Entrepreneurship, E-commerce, Internet. 


\section{INTRODUÇÃO E OBJETIVO}

Mediante a imposição do fenômeno da globalização cujo propósito foi de possibilitar as relações comerciais, econômicas e sociais entre países e pessoas de todo o mundo, e as constantes tentativas de estabilização na economia brasileira, registradas a partir de 1980, grandes organizações, responsáveis por parte considerável dos empregos, principalmente nas metrópoles, tiveram de adotar estratégias para elevar sua competitividade perante a concorrência, buscando a diminuição dos custos, bem como a preferência dos consumidores.

A partir dessas dificuldades, dado o grande número de concorrentes advindos das fronteiras abertas pela globalização, muitas organizações empresariais não resistiram e tiveram de encerrar suas atividades, dispensando a mão de obra de milhares de trabalhadores; ocasionando um elevado índice de desemprego, principalmente nos grandes centros urbanos.

Dada à situação em que encontravam-se, muitos destes trabalhadores, à fim de garantir seu sustento, bem como de sua família, arriscaram-se, mesmo sem qualquer tipo de capacitação ou experiência e abriram seu próprio negócio, dando início a onda de empreendedorismo no país, que é vivenciada até o presente momento.

Devido à falta de conhecimento, muitos destes novos empreendedores operavam na informalidade e eram responsáveis pelo altíssimo índice de mortalidade destas micro e pequenas empresas, logo no primeiro ano. Observadas as dificuldades as quais estes se deparavam, o governo, juntamente com entidades de classe, passaram a apoiar direta e indiretamente estes novos empresários e ofereceram-lhes oportunidades de capacitação e consultoria, a fim de que a empresa prosperasse e pudesse oferecer novas oportunidades de emprego e geração de renda.

A partir de 1995, uma nova oportunidade foi criada e por meio da internet tornou-se possível a prática de comércio online. Muitos empreendedores, atraídos pelo baixo investimento necessário para abertura do negócio, lançaram-se neste novo segmento, e passaram a ofertar seus produtos e serviços por meio da rede mundial de computadores.

O comércio eletrônico, embora atrativo, pode ser considerado igualmente complexo. Os empreendedores que pretendem investir neste nicho de mercado devem ter uma visão geral sobre sua pretensão de negócio, bem como atualizar-se em relação às tendências de mercado e a economia mundial, mantendo-se preparados para identificar oportunidades e assumir riscos.

Ainda que favoreça a competitividade nos negócios e possibilite as transações comerciais entre empresas e consumidores finais, resultando em benefício tanto para a própria organização quanto para os clientes, o comércio eletrônico ainda enfrenta uma série de barreiras impostas ao 
seu funcionamento que devem ser combatidas por meio de estratégias que permitam à organização sobressair-se perante a concorrência e conquistar a confiança dos seus clientes.

Dessa forma, o comércio eletrônico, além de beneficiar os usuários, oferecendo-lhes a comodidade da ubiquidade, conquistou também os empreendedores que enxergaram neste segmento uma maneira inovadora de ofertar seus produtos e serviços. Porém, apesar de contribuir visivelmente para o desenvolvimento da economia, muitos obstáculos permanecem sendo criados e somente um empreendedor bem preparado poderá administrar recursos suficientes para superá-los e alcançar o sucesso da organização.

Desta forma, essa pesquisa tem por objetivo, demonstrar de que maneira o empreendedorismo por ser aplicado às práticas de comércio eletrônico, visando essencialmente o perfil do empreendedor e as dificuldades enfrentadas por quem opta por este tipo de negócio.

\section{METODOLOGIA}

A pesquisa é um procedimento reflexivo, sistemático, controlado e crítico que permite descobrir novos fatos ou dados, soluções ou leis, em qualquer área do conhecimento. (RAMPAZZO, 2004, p. 49). Portanto, além de proporcionar o enriquecimento cultural adquirido mediante a realização da pesquisa, este trabalho tem por finalidade, agregar maior valor ao tema proposto, podendo ser útil na minimização dos problemas encontrados, assim como na gama de soluções possíveis às organizações.

Segundo Köche, (2012, p. 126), “o objetivo fundamental de uma pesquisa exploratória é o de descrever ou caracterizar a natureza das variáveis que se quer conhecer." Portanto, presumese que este tipo de pesquisa possibilita a familiarização do autor para com o tema escolhido e permite que este exponha suas ideias com maior autoridade e domínio sobre o assunto.

Nessa perspectiva, verifica-se que esta pesquisa foi efetuada de forma exploratória, visando à apresentação superficial do tema ao leitor e buscando analisar se a teoria apresentada é compatível com a atual situação vivenciada pelas organizações. Sendo assim, somente a partir desta análise preliminar, foi possível buscar a confirmação das hipóteses levantadas e a garantia da veracidade dos fatos apresentados.

No entanto, a abordagem desta pesquisa foi qualitativa, pois procurou conceituar e definir o papel do empreendedor em meio ao comércio eletrônico, bem como abordar o diferencial que este proporciona à organização mediante ao seu desenvolvimento.

Conforme Rampazzo (2004, p. 58), “[...] a qualitativa busca uma compreensão particular daquilo que estuda: o foco da sua atenção é centralizado no específico, no peculiar, no individual, 
almejando sempre a compreensão e não a explicação dos fenômenos estudados". Sendo assim, por meio desta ferramenta, o pesquisador elabora seu texto de maneira cuidadosamente organizada, a partir de estudos científicos baseados no objeto da pesquisa.

Complementarmente, utilizou-se neste trabalho o método de estudo de caso. Realizou-se por meio de um delineamento entre a análise prática e a fundamentação teórica, a fim de possibilitar uma melhor compreensão dos dados coletados.

Importante salientar que o estudo de caso "Consiste no estudo profundo e exaustivo de um ou poucos objetos, de maneira que permita seu amplo e detalhado conhecimento" (GIL, 2010, p. 37). Logo, entende-se que por meio do estudo de caso o pesquisador adquire argumentos suficientes para ir além da teoria e expor a realidade social abordada pela pesquisa bibliográfica.

\section{RESULTADO}

Para o melhor desenvolvimento da pesquisa e dada sua devida importância, considerou-se essencial à sua elaboração, a abordagem aos dois proprietários da organização, que passaram a compor a amostra selecionada.

Desta forma, em relação ao empreendedorismo, ambos posicionaram-se afirmando que o papel do empreendedor é superar os conceitos já existentes, inovando as práticas implementadas, em busca de melhorias constantes à organização.

Mais do que isso, conforme Degen (2005), empreender é ter necessidade de realizações, de colocar em prática suas próprias ideias, portanto, cabe ao empreendedor munir-se de conhecimento e manter-se em constante desenvolvimento, a fim de cultivar a prosperidade do seu negócio, visando à efetiva inovação de suas práticas, com o propósito de destacar-se perante a concorrência.

Embora reconheçam a importância das assessorias de apoio ao empreendedor, os proprietários da empresa estudada, consideram que tais auxílios sejam direcionados às pessoas que não possuem experiência no ramo de atuação pretendido ou que estejam em dúvida sobre as peculiaridades da atividade a ser exercida. Porém, de acordo com a legislação vigente, publicada em 9 de outubro de 1990, quanto as atribuições do SEBRAE, o art. 2o do decreto no 99.570 define que o papel da instituição perante à sociedade é planejar, coordenar e direcionar atividades de apoio às micro e pequenas empresas, independente de seu segmento, ou período de atuação. Com isso, torna-se evidente que embora o foco do SEBRAE esteja voltado aos empreendedores que se encontram em dificuldades devido principalmente aos primeiros anos de abertura do negócio e a alta taxa de mortalidade neste período, qualquer indivíduo pode recorrer aos serviços 
prestados pela instituição, independentemente se inexperientes ou não e solicitar apoio quanto as estratégias para abertura, gestão e crescimento das organizações.

Ainda que propenso a inúmeras oportunidades e facilitador em diversos sentidos, principalmente no que diz respeito à comodidade e economia, o comércio eletrônico exige profissionais cada vez mais preparados, qualificados e dispostos a assumir riscos. O planejamento do negócio, a análise do mercado e a disponibilidade de recursos podem ser considerados os principais aspectos a serem destacados para abertura de uma empresa, independentemente se convencional ou eletrônica. Neste sentido, quanto as maiores dificuldades enfrentadas, ambos listaram a falta de planejamento e/ou estudo detalhado sobre o negócio e a ampla concorrência existente.

Por fim, referindo-se às vantagens do comércio eletrônico em relação ao empreendimento físico, os empreendedores posicionaram-se observando quanto a necessidade de um menor número de funcionários, bem como a importância reduzida de sua localização física, visto que não há necessidade em posicionar-se nos grandes centros urbanos.

Além dos benefícios elencados pelos proprietários da empresa estudada, pode-se considerar a inexistência de gestão de estoque como uma das principais características benéficas sobre os demais empreendimentos. Considerando que a organização estudada realiza transações somente com o governo do estado de São Paulo por meio da Bolsa Eletrônica de Compras, os materiais comercializados são adquiridos somente após o ganho da licitação, e entregues diretamente na instituição compradora, sem necessidade de armazenagem e transporte dos mesmos.

Desta forma, a fim de possibilitar o desenvolvimento sólido do comércio eletrônico, muito se tem investido neste segmento de mercado e sua expressiva taxa de crescimento pode ser considerada prova suficiente que o e-commerce não refere-se a uma tendência passageira e sim a uma revolução no mundo dos negócios.

\section{DISCUSSÃO}

Após analisar o cenário em que se encontram as empresas direcionadas ao comércio eletrônico e delinear o perfil do empreendedor que opta por este segmento em busca de liberdade profissional e autonomia, considerando as vantagens e dificuldades com que estes se deparam na abertura e desenvolvimento do negócio, percebeu-se, pelos resultados da pesquisa, que a empresa, objeto de estudo deste trabalho, embora não efetue transações diretamente com o consumidor final ou outras empresas, mas única e exclusivamente com o governo e entidades 
inter-relacionadas, enfrenta dificuldades igualmente relevantes e necessita constantemente de monitoramento em seus processos, visto a ampla concorrência presente no segmento atuante. Por outro lado, a organização goza de benefícios singulares ao comercializar diretamente com o Estado, eximindo-se de qualquer risco referente à inadimplência, baseando-se em normas préestabelecidas de acordo com edital divulgado antecipadamente pela instituição.

No entanto, após análises criteriosas às rotinas da empresa, notou-se a necessidade em desenvolver a profissionalização da organização, implementando práticas de processos e procedimentos que visem à normatização do cotidiano organizacional, de modo a antecipar-se a situações futuras e manter-se preparada às variáveis decorrentes do mercado, bem como institucionalizar os princípios essenciais à organização, tais como missão, visão e valores, projetando resultados e almejando patamares superiores.

Outro fato que merece destaque é a necessidade de constante atualização profissional, dada relação intrínseca que este negócio possui com as condições legais e regulamentares emanadas pelos editais, o que pode, sobretudo, ser considerado um ponto de atenção.

\section{CONCLUSÃO}

A partir da pesquisa realizada, tornou-se evidente a importância do empreendedorismo em meio ao cenário atual, e sua contribuição à economia, abrangendo desde empreendimentos físicos, até organizações eletrônicas.

Embora atuante no mercado há menos de três anos, a organização estudada pode ser considerada sólida e estruturada, visto suas práticas e seu embasamento organizacional.

Em meio às vantagens deste empreendimento em relação a uma organização convencional, com processos e rotinas executadas num ambiente físico, a que mais se sobressai, é a inexistência de gestão de estoque e a economia que esta prática representa à empresa, fazendo com que a mesma tenha o foco de seu negócio totalmente empregado em suas rotinas comerciais.

Assim, pode-se concluir que embora ofereça maiores facilidades e ganhe cada vez mais adeptos devida comodidade oferecida e desenvolvimento constante de suas funcionalidades, o comércio eletrônico exige de seus empreendedores, o mesmo esforço e dedicação de qualquer outro empreendimento e oferece uma série de segmentos ligados às suas plataformas online, permitindo portanto, que o próprio empreendedor escolha o que mais se identifique às suas necessidades. 


\section{REFERÊNCIAS}

BRASIL. Decreto n.o 99.570, de 9 de outubro de 1990. Desvincula da Administração Pública Federal o Centro Brasileiro de Apoio à Pequena e Média Empresa - CEBRAE, transformando-o em serviço social autônomo. Disponível em: <http://www.camara.gov.br/sileg/integras/211766.pdf>. Acesso em: 26 jul. 2013.

DEGEN, D. O empreendedor: fundamentos da iniciativa empresarial. 8. ed. São Paulo: Pearson, 2005.

KÖCHE, J. C. Fundamentos de metodologia científica: teoria da ciência e iniciação à pesquisa. 31 . ed. Petrópolis: Vozes, 2012.

GIL, A. C. Como elaborar projetos de pesquisa. 5. ed. São Paulo: Atlas, 2010.

RAMPAZZO, L. Metodologia científica: para alunos dos cursos de graduação e pós-graduação. 2. ed. São Paulo: Edições Loyola. 2004. 